\title{
Reading for Pleasure as a Means of Improving Reading Comprehension Skills
}

\author{
Shazila Abdullah ${ }^{1}$, Puteri Rohani Megat Abdul Rahim ${ }^{1}$, Roszainora Setia ${ }^{2}$, Razita Mohamad ${ }^{2}$, Norliana Ghazali ${ }^{2}$, \\ Elangkeeran Sabapathy ${ }^{2}$, Gopala Krishnan Sekharan Nair $^{2}$, Mohan K. Muniandy ${ }^{3}$, Ramachandran Theethappan ${ }^{3}$, \\ Wan Aida Wan Hassan ${ }^{4} \&$ Nor Syamimi Iliani Che Hassan ${ }^{4}$ \\ ${ }^{1}$ Academy of Language Studies, Universiti Teknologi MARA, Bota, Malaysia \\ ${ }^{2}$ Academy of Language Studies, Universiti Teknologi MARA, Dungun, Malaysia \\ ${ }^{3}$ Academy of Language Studies, Universiti Teknologi MARA (UiTM), Kuala Pilah, Negeri Sembilan, Malaysia \\ ${ }^{4}$ Academy of Language Studies, Universiti Teknologi MARA (UiTM), Machang, Kelantan, Malaysia \\ Correspondence: Gopala Krishnan Sekharan Nair, Academy of Language Studies, Universiti Teknologi MARA, \\ 23000 Dungun, Terengganu, Malaysia. E-mail: gopal792@tganu.uitm.edu.my
}

Received: March 14, 2012 Accepted: July 5, 2012 Online Published: October 26, 2012

doi:10.5539/ass.v8n13p233

URL: http://dx.doi.org/10.5539/ass.v8n13p233

\begin{abstract}
Reading has always been an important skill for university students in order for them to gain access to knowledge in the academic books. Despite this, many students who view reading in English as important do not actually engage themselves in English reading activities outside class hours. Reading for pleasure allows learners to acquire certain language skills. Therefore, an experimental study using reading for pleasure was conducted. The experimental group was exposed to reading for pleasure for 5 weeks, while the other group was not. However, the control group showed better improvement of comprehension skills in the post test. Whereas, the pre-test scores results were nearly the same. The reasons for this are explained in the discussion that follows. From questionnaires distributed, a substantial number of subjects (79\%) said that reading for pleasure would help them to understand the text better and they would pursue reading for pleasure. It is hoped that this small-scale study would highlight the effect of reading for pleasure in improving the students' reading comprehension skills. Future researchers should cover an experimental study which is of longer duration. A period of six months is suggested.
\end{abstract}

Keywords: ESL, reading for pleasure, reading comprehension, vocabulary

\section{Introduction}

Reading is the most integral part in language learning. It enables students of a higher learning to open the window to the outside world as readers with strengthened reading skills will be able to progress and attain greater development in all academic areas. However, many students who enter post-secondary institutions do not display advanced literate behaviors and are therefore under-prepared to function successfully in an academic context Wyatt (1992).

In learning English as a second or foreign language, Anderson (1999), asserts that reading is the most important skill to master. In Malaysia, where English is taught as a second language, reading in English would undoubtedly help a learner to be proficient in the language as language can be learned through reading Fatimah and Vishalache (2006). Nevertheless, a few surveys on reading habits in Malaysia showcased that tertiary level students spent less time reading than they used to before joining the university Sarjit and Rosy (1999). A similar result was found in a reading habit survey Puteri Rohani M.A. Rahim, Shazila Abdullah \& Shareena Mohamed Has (2007). The survey indicated that even though most subjects had high level of motivation and attitude, only about two third of the subjects did spend time on reading English materials outside class hours. But out of this two third who spent time on reading, almost half of them spent only less than1 hour a week on English reading.

Poor readers are not only reluctant to read, but they also often score poorly in performance tests. The failure in answering reading comprehension questions correctly could only indicate that they failed to understand the given texts. 
Therefore, this study will look at how teachers could help learners understand a reading passage by highlighting certain reading strategies in class. It is hoped that subjects would employ these reading strategies when doing independent reading.

\section{Literature Review}

\subsection{Reading Comprehension and Reading Strategies}

Many ESL learners fail to see reading comprehension as an active process. Reading does not merely mean decoding the text into words as it involves certain strategies and behaviors (Pressley, 2000). Many syllabuses for reading in ESL outline the sub-skills of reading comprehension, among which are making inferences, predicting and making conclusions. To comprehend a reading text, learners should integrate the skills and apply certain strategies in doing so.

According to Pressley (2000), some of the reading comprehension strategies that learners could employ when doing independent reading are "prior knowledge activation, question generation and construction of mental images during reading". When interest is well developed, the level of reading comprehension may also increase.

From this, it can be deduced that in order to improve reading comprehension, ESL learners need to do a lot of reading and actively participate in the reading process. Handouts published by offer some guidelines on reading strategies that can be adopted and adapted to fulfill the purpose of interacting with the text.

\subsection{Reading for Pleasure}

Good readers read and understand. Recent developments in improving comprehension have focused on promoting extensive reading that requires readers to read a quantity of SL materials over a period of time Bright and McGregor (1977). Krashen (1993), study on free voluntary reading in many different countries shows an improvement in reading comprehension. A similar result was also reported in Hayashi (1999), study on the effects of extensive reading on Japanese university students' proficiency in English. It was found out that students who read more English books showed a major improvement in reading ability than those who read less.

According to Sheu (2004), reading extensively allows students to apply reading strategies they learn in skill-based instruction. A survey on reading habits of UiTM students in Perak Puteri Rohani M.A. Rahim, Shazila Abdullah \& Shareena Mohamed Has (2007), reveals that only about 27\% of the subjects read daily. It is also as disheartening to find out that $4 \%$ of the subjects almost or never read at all outside class hours.

To address this issue, teachers should encourage students to engage in reading for pleasure. It has been mentioned earlier that students of higher learning chose not to read in English due to insufficient time and the difficulty in understanding the text. What will then make these reluctant readers read for pleasure? According to Nell (1988), in order for students to take up reading for pleasure, they should have reading ability, positive expectations of the activity and correct book selection.

\subsection{Reading Motivation and Reading Interest}

Reading motivation refers to a person's personal goals, values and beliefs on reading topics, processes and outcomes Guthrie and Wigfield (2000).

Motivation can be in the form of intrinsic (internal) and extrinsic (external) factors. When the desire to read is controlled externally, for example, to meet teachers' or parents' expectations, readers are only extrinsically motivated because they may not be interested to read but they want to achieve certain outcomes like rewards or good grades Deci, Koestner \& Ryan (1999).

Motivation is also closely related to why students read. There can be various reasons why students are motivated to read in English. In UiTM, students need to read in English as textbooks and references are mostly in English, which is the university's requirement. Here, extrinsic reinforcement with better grades for the course assignments will be the motivation for students to read Fatimah and Safiah (1987). However, for reading for pleasure to occur, it requires one to have more than extrinsic motivation. Besides motivation, reading interest plays an important role in fostering reading for pleasure. It refers to the choice of reading materials according to one's preference or interest. Hence, the subjects in this study will also be allowed to choose their own reading materials and read anywhere and anytime convenient to them. In summary, the focuses of this study are on:

1) Assisting students to aid reading comprehension through certain reading strategies

2) Encouraging students to be engaged in reading for pleasure

By this, the researchers hope to find out:

1) If by applying certain reading strategies learned in class in reading for pleasure, students are able to improve 
reading comprehension

2) The perception of students' on reading for pleasure

\section{Methodology}

In this experimental study, a quantitative research design using performance tests and a questionnaire were used. Two groups were randomly selected; one of which was asked to take up reading for pleasure for a period of 5 weeks, while the other group, which was the control group, was not exposed to any approach of intervention. Both groups were given a pre-test and post test in order to determine the level of improvement of their reading comprehension skills. Questionnaires pertaining to reading for pleasure were also distributed prior to the onset and upon completion of the project to gauge the students' perception and interest in reading for pleasure.

\subsection{Selection of Subjects}

Subjects were selected randomly from two different groups of Art and Design Faculty at UiTM Perak. A total of 48 students took part in this study which comprised 24 students in the Experimental Group and 24 students in the Control Group. The subjects are all diploma students in part 3 that range between the ages of 18 to 20 years old. Their English level proficiency is of mixed ability based on their Part 2 English result.

\subsection{Procedure}

At the beginning of the semester:

Subjects in both experimental and control groups were given a Reading Test (Pre-Test), which was the Reading Section of the English subject Final Exam for Part 3 students the previous semester. However, subjects in the Experimental Group participated in a reading project prior to the Post-Test. They were told about the 'Reading Project' after completing the Pre-Test. Subjects were then:

1) Informed what 'reading for pleasure' was about given a questionnaire (Questionnaire 1) to find out their reading habit and attitude in general

2) Asked to take up reading for pleasure for a period of 5 weeks, including outside class hours

3) Explained about the benefits of reading for pleasure and focus of the project, which was to aid reading comprehension

4) Told to collect a vast selection of reading materials that interest them

5) Given a 'Reading Project Portfolio File' each to compile their reading materials

6) Informed about what a Reading Journal is as they were required to include it in their portfolio

As the Reading Project progressed:

1) Subjects were given half an hour twice a week at the beginning of the English class to do reading for pleasure. They could read any reading material of their own choice.

2) Subjects were encouraged to discuss, talk and share their knowledge of what they had read with each other

3) Two shared reading sessions were conducted by the teacher, in which she demonstrated a range of comprehension strategies, that included 'think-aloud' to formulate questions prior to reading and in response to the text, 'inferential reading' to draw upon prior knowledge, draw conclusions and make inferences, and 'reading journal' to encourage students to write their own view of the text and how they relate to it, thus making connection with the text.

4) In the period of reading for pleasure in class, subjects were offered guidance by the teacher. To ensure that they actively engage with the text, they were encouraged to 'think-aloud', even with the teacher.

5) To make it much easier and clearer for the subjects to apply the reading strategies, the teacher often told them to 'think, read, talk, think (again) and write' (TRTTW) which would generally sum up the reading strategies learned earlier

6) Subjects were constantly reminded to TRTTW when doing their own independent reading outside class hours. At the end of the Reading Project:

1) The Reading Project Portfolio File was collected from each subject.

2) They were given a questionnaire (Questionnaire 2) to find out their post overall view on reading for pleasure.

After the completion of the Reading Project, subjects in both control and experimental groups were again given the same Reading Test (Post-Test). 


\section{Results and Discussion}

The questionnaires and performance test results were analyzed using SPSS version 11.5 programme. The frequency and percentage distribution of the responses were calculated. Since this study focuses on reading for pleasure only relevant questions were selected for discussion.

\subsection{Pre-test and Post-test Results of the Experimental and Control Groups}

As illustrated in Table 1 prior to the intervention approach the results of the Pre-test indicated that both Control and the Experimental groups obtained almost similar score in their performance. $67 \%$ of the Experimental Group scored poor, while in the Control Group 55.6\% obtained poor score. Only 33\% achieved low score in the Experimental Group and their counterparts got $40.7 \%$ under the same category.

Table 1. A comparison of pre-test and post-test scores for the experimental and control groups

\begin{tabular}{ccccccccc}
\hline Score level & \multicolumn{2}{c}{ Pre-Test } & \multicolumn{2}{c}{ Pre-Test } & \multicolumn{2}{c}{ Post-Test } & \multicolumn{2}{c}{ Post-Test } \\
\hline & \multicolumn{2}{c}{ Exp. Gp } & \multicolumn{2}{c}{ Control Gp } & \multicolumn{2}{c}{ Exp. Gp } & \multicolumn{2}{c}{ Control Gp } \\
& \multicolumn{2}{c}{ n $=24$} & \multicolumn{2}{c}{$\mathrm{n}=27$} & \multicolumn{2}{c}{$\mathrm{n}=24$} & \multicolumn{2}{c}{$\mathrm{n}=27$} \\
& Freq & $\%$ & Freq & $\%$ & Freq & $\%$ & Freq & $\%$ \\
P & 16 & 67 & 15 & 55.6 & 8 & 33.3 & 2 & 7.4 \\
L & 8 & 33 & 11 & 40.7 & 15 & 62.5 & 11 & 40.7 \\
M & 0 & 0 & 1 & 3.7 & 1 & 4.2 & 11 & 40.7 \\
H & 0 & 0 & 0 & 0 & 0 & 0 & 3 & 11.2
\end{tabular}

Key: P- poor $\bullet$ L-low $\bullet$ M-Medium $\bullet$ H-high

However, after the intervention approach the result displayed in Table 1 showed otherwise. Subjects in the Control Group obtained better results than their counterparts in the Experimental Group. Majority of the students in Control Group obtained either low score or medium which constitute to $81.4 \%$. For the Experimental Group $62.5 \%$ scored low and another $33.3 \%$ obtained poor score. After the approach, only $4.2 \%$ of the Experimental Group managed to get medium score. While, $11.2 \%$ of the Control Group managed to get high score for their post-test.

A paired sample t-test was conducted. As shown in Table 2 the result displays that the Control Group performance was significantly better then the counterparts' results in the Experimental Group. The Experimental Group's $\mathrm{t}$ value is $1.989, \mathrm{df}=23, \mathrm{p}>.059$. The Control Group obtained t value, $7.706, \mathrm{df}=26, \mathrm{p}<.005$, which indicates that the results of the Post-test and Pre-test of the group is significant. Therefore, the intervention approach of using reading for pleasure has not improved the reading Comprehension skills amongst the subjects in the Experimental Group.

Table 2. Means, standard deviations and t-value of percentage score of the pre-test and post-test of the experimental and control groups

\begin{tabular}{cccccc}
\hline & Mean Scores & SD & t-value & df & $\mathrm{p}$ \\
\hline Experiment & .37500 & .92372 & 1.989 & 23 & .059 \\
Control & .96296 & .64935 & 7.706 & 26 & .000 \\
\hline
\end{tabular}

4.2 Analysis of Questionnaire 1 and Questionnaire 2

Table 3. Results of questionnaire $1(\mathrm{n}=24)$

\begin{tabular}{lc}
\hline \multicolumn{1}{c}{ Summary of answers: } & Frequency *(in \%) \\
\hline Reading in English is important & $100 \%$ \\
Subjects read in English to improve proficiency. & $54 \%$ \\
Subjects read English materials beside text and reference books during pastime. & $58 \%$ \\
Subjects often read - at least 5 times a week. & $13 \%$ \\
Subjects do not read because of the inability to understand the text. & $55 \%$ \\
Reading a lot of English materials will help to understand reading passages better. & $96 \%$ \\
\hline
\end{tabular}

Table 3 displays subjects' overall view on English reading. As expected, all the subjects are aware of the 
importance of reading in English, which could also mean that they would be intrinsically motivated to read. More than half of the subjects also (54\%) realized that reading in English can improve their proficiency. However, due to time constraint and other important tasks to do, only $58 \%$ of the subjects read English materials beside text and reference books during pastime and from this just a mere $13 \%$ of them often read. $55 \%$ of the subjects who did not read feared they that might not understand what they read. Nevertheless, almost all subjects agreed that reading extensively in English would help to improve reading comprehension.

Table 4. Results of questionnaire $2(\mathrm{n}=24)$ frequency * (in percentage)

\begin{tabular}{lccc}
\hline Question: & $\begin{array}{c}\text { Agree/ Strongly } \\
\text { agree }\end{array}$ & Not sure & $\begin{array}{c}\text { Disagree/ } \\
\text { Strongly disagree }\end{array}$ \\
\hline I enjoyed reading the articles that I had chosen. & $83 \%$ & $17 \%$ & - \\
The articles that I chose to read were interesting to me. & $83 \%$ & $12.5 \%$ & $4.5 \%$ \\
I felt satisfied after reading the articles that I liked. & $92 \%$ & $8 \%$ & - \\
I always looked forward to reading another one after I & $54 \%$ & $38 \%$ & $8 \%$ \\
had finished reading an article. & & $12.5 \%$ & $10.5 \%$ \\
I have never read as many English articles within 5 & $75 \%$ & $21 \%$ & - \\
weeks as I had for this project. & $79 \%$ & $21 \%$ & - \\
$\begin{array}{l}\text { After doing this project, I feel I can understand a } \\
\text { reading text better now. }\end{array}$ & & \\
$\begin{array}{l}\text { I will continue reading for pleasure during my own } \\
\text { free time from now on. }\end{array}$
\end{tabular}

Subjects' overall view on the Reading Project and reading for pleasure is displayed in Table 4. It is interesting to note that a large percentage of the subjects $(88 \%)$ read the collection of articles outside class hours at least once a week. One even claimed that he/she read the articles at least once a day. A large percentage of subjects (83\%) also associated enjoyment with reading for pleasure and this could be because they perceived the articles that they read as interesting (83\%). Besides, the frequency of satisfaction after reading the articles is also high (92\%). But only slightly more than half of the subjects (54\%) would look forward to read another article. Since more than half of the subjects said that they never read in English for pleasure in the earlier questionnaire, it came to no surprise that $75 \%$ of them had never read as many English articles as they had for the project. A substantial number of subjects (79\%) also said it would help them to understand reading text better and they would pursue reading for pleasure.

\section{Conclusion}

From the analysis of Pre-test and Post-test results of the experimental group, no marked difference was shown, whereas subjects in the Control Group showed quite a marked improvement in the post-test result despite having no form of intervention during the lapse of pre-test and post-test. This could be due to the presence of extrinsic motivation as the teacher expected them to do better than their pre-test result and they may have in-built strategies which they might have acquired during the years of English learning.

On the other hand, even though subjects in the Experimental Groups showed positive attitudes towards reading for pleasure as a whole and were guided on how to employ reading strategies to aid comprehension in the course of the Reading Project, the results of the performance tests indicated otherwise. The same result was also found in study in which they noted that reading amount is not a predictor for text comprehension. Thus, it is feared that these subjects might have chosen articles that were below their competency level and might not have employed the reading strategies when engaging in reading for pleasure. Hence, this could explain the outcome of the post-test result. All of this points to one important criterion in using reading for pleasure to improve reading comprehension skills: time. 5 weeks of reading for pleasure may not be sufficient to improve any language skills, let alone reading comprehension. That is why ESL learners who lack reading practice which hampers learning development are unable to read fluently outside the classroom.

Perhaps the most important implication of this study is the positive attitudes towards reading for pleasure shown by experimental subjects. This newly developed interest in reading English materials outside class hours could then develop students into becoming a life-long reader. The recognition of the value of reading for pleasure suggests that teachers, policy makers and curriculum designers alike should promote reading motivation through reading for pleasure and not perceive reading as an activity without merit. At the same time, teachers should 
design and implement activities that could provide explicit instruction to support comprehension as it is important to employ reading strategies while engaging in authentic reading like reading for pleasure and not as a separate set of skills.

\section{References}

Anderson, N. (1999). Exploring Second Language Reading: Issues and Strategies. Canada: Heinle \& Heinle Publishers.

Bright, J. A., \& Mcgregor, G. P. (1977). Teaching English as a second language. London: Longman.

Deci, E. L., Koestner, R., \& Ryan, R. M. (1999). A meta-analytic review of experiments examining the effects of extrinsic rewards on intrinsic motivation. Psychological Bulletin, 125, 627-668. http://dx.doi.org/10.1037/0033-2909.125.6.627

Fatimah, H. D., \& Safiah, O. (1987, December). Reading and National Development: What the Universities can do. English Teacher, XVI.

Fatimah, H., \& Vishalache, B. (2006). Language Immersion for Language Proficiency ESL Learners: The Alemac Project. Reading Matrix, 6(2).

Guthrie, J. T., \& Wigfield, A. (2000). Engagement and motivation in reading. In Kamil, M. L., Mosenthal, P. B., Pearson, P. D., \& Barr, R. (Eds.), Handbook of Reading Research (3rd ed.). New York: Longman.

Hayashi, K. (1999). Reading Strategies and extensive reading in EFL classes. RELC Journal, 30, 114-132. http://dx.doi.org/10.1177/003368829903000207

Krashen, S. (1993). The Power of Reading. Englewood, CO: Libraries Unlimited.

Nell, V. (1988). The psychology of reading for pleasure: Needs and gratifications. Reading Research Quarterly, 23, 6-50. http://dx.doi.org/10.2307/747903

Pressley, M. (2000). What should comprehension instruction be the instruction of? Handbook of Reading Research, III, 545-559.

Rahim, P. R. M. A., Shazila, A., \& Shareena, M. H. (2007, December). A Survey in Reading Habits in UiTM Perak. Paper presented at the 5th UiTMT Academic Conference, Terengganu Equastrian Resort.

Sarjit, K., \& Rosy, T. (1999, September). The English Reading Habits of ELLS Students in University Science Malaysia. Paper presented at the Sixth International Literacy and Education Research Network Conference, Bayview Beach Resort, Penang, Malaysia.

Sheu, S. P-H. (2004). The Effects of Extensive Reading on Learners' Reading Ability Development. Journal of National Taipei Teachers College, 17(2).

Wang, J. H. Y., \& Guthrie, J. T. (2004). Modelling the effects of intrinsic motivation, extrinsic motivation, amount of reading, and past reading achievement on text comprehension between U.S. and Chinese students. Reading Research Quarterly, 39, 162-186. http://dx.doi.org/10.1598/RRQ.39.2.2

Wyatt, M. (1992). The past, present, and future need for college reading courses. U.S. Journal of Reading, 36(1), 10-20. 